\title{
RELAÇÃO ENTRE A DIETA ALIMENTAR E O DESENVOLVIMENTO DA CÁRIE DENTÁRIA EM ESCOLARES: UMA REVISÃO DE LITERATURA
}

\author{
Mariana Luise Ferreira de Andrade 1 , Allana Wenzel Giollo², \\ Leomar Emanuel Almeida Mecca³, Graziela Nunes4.
}

${ }^{1}$ Acadêmica do Curso de Nutrição, Centro Universitário de Maringá - UNICESUMAR - Campus Ponta Grossa. Bolsista PIC. mari Ifa@hotmail.com

\footnotetext{
${ }^{2}$ Acadêmica do Curso de Odontologia, Centro Universitário de Maringá - UNICESUMAR - Campus Ponta Grossa. Bolsista PIC. allanawenzel@hotmail.com

${ }^{3}$ Professor mestre do curso de odontologia e coorientador do projeto, Centro Universitário de Maringá - UNICESUMAR - Campus Ponta Grossa. leomar.mecca@unicesumar.edu.br

${ }^{4}$ Professora mestre do curso de nutrição e orientadora do projeto, Centro Universitário de Maringá - UNICESUMAR - Campus Ponta Grossa.graziela.nunes@unicesumar.edu.br
}

\section{RESUMO}

O presente estudo tem por objetivo produzir uma revisão de literatura sobre a influência da alimentação no desenvolvimento da cárie dentária em escolares, a partir da dieta oferecida em creches e escolas. Ambientes educacionais são locais estratégicos para evoluir o conhecimento dos infantes sobre a promoção da saúde, criação de bons hábitos alimentares e higiene bucal. Uma dieta infantil com elevado teor de sacarose é um fator determinante no aparecimento da cárie. Isso, porque proporciona um ambiente favorável à desmineralização dos dentes e consequentemente ao surgimento da doença. Diante disso, conclui-se que a alimentação atua efetivamente no aparecimento da cárie e o conhecimento de educadores e merendeiras é primordial para transmitir aos alunos os cuidados necessários para promover a saúde bucal.

PALAVRAS-CHAVE: Alimentos; Cárie; Escolares.

\section{INTRODUÇÃO}

O ambiente escolar reflete um espaço ideal para ações de promoção à saúde tal qual o incentivo de práticas adequadas de higiene oral e alimentação saudável (GARBIN et al., 2013). É essencial salientar que a dieta alimentar está intimamente ligada ao processo de formação da cárie. Sendo assim, o aconselhamento dietético é primordial para a manutenção da saúde bucal, uma vez que são adquiridos na infância e constituem a base para um crescimento e desenvolvimento adequados (FElJÓ et al., 2014).

A cárie pode ser compreendida como uma doença complexa e multifatorial, dependente de quatro condições básicas: o substrato cariogênico, o microrganismo, o período em que o dente estará suscetível a interação e formação do processo carioso. Por conseguinte, a desmineralização dos tecidos dentários é proveniente da fermentação ocasionada pelos resíduos alimentares, especialmente a sacarose (CARVALHO et al., 2018). Esse processo aumenta a viscosidade do biofilme dentário facilitando a adesão do microrganismo no dente (FERREIRA et al., 2018).

Na infância, a cárie é observada com maior prevalência. A partir dos seis meses de idade hábitos alimentares são adquiridos e em muitos casos há a presença do açúcar, podendo ocasionar a cárie, uma vez que esta é sacarose dependente (FERREIRA et al., 
2018). Ademais, dados levantados pelo Ministério da Saúde apontam que $60 \%$ das crianças com cinco anos de idade apresentam cárie (Ministério da Saúde, 2014).

Os educadores e merendeiras são, portanto, indispensáveis no processo de desenvolvimento de bons hábitos alimentares e educação em saúde bucal, posto que estes profissionais possuem um vínculo afetivo com os infantes devido ao tempo que ficam sob seus cuidados (VENÂNCIO et al., 2011).

De posse dessas informações, o presente estudo tem por objetivo produzir uma revisão de literatura sobre a influência da alimentação no desenvolvimento da cárie dentária em escolares, a partir da dieta oferecida no ambiente escolar.

\section{MATERIAIS E MÉTODOS}

Como estratégia de busca para seleção dos estudos recentes (últimos 4 anos), foram consultadas as bases de dados Portal Capes (Coordenação de Aperfeiçoamento de Pessoal de Nível Superior) e SciELO (Scientific Eletronic Library Online) publicados entre 2014 e 2018. Os seguintes descritores foram utilizados devido à sua recorrência na indexação de artigos envolvendo o tema: alimentos, cárie e escolares. Ao final da análise 5 estudos atenderam aos critérios de inclusão e exclusão, sendo avaliados no presente estudo. Foram incluídos os artigos com delineamento observacional, realizados em ambientes educacionais, nos quais foram avaliados a alimentação, interação educadoraluno, sensibilização dos responsáveis sobre dieta alimentar e hábitos de higiene bucal, além disso, fatores estimulantes do desenvolvimento da doença cárie. Artigos que não relacionaram a dieta alimentar e a higiene oral, exclusivamente, em creches e/ou escolas foram excluídos.

\section{$3 \quad$ RESULTADOS E DISCUSSÕES}

Os estudos tiveram como resultados comprovados que a alimentação saudável deve ser implantada na primeira infância. Deve-se realizar as trocas de alimentos ultraprocessados, que contém adição de sacarose, por alimentos in natura, que evitam o aparecimento da doença (LIMA; GONÇALVES; CORREIA, 2015).

Uma pesquisa realizada por Scalioni (SCALIONI et al., 2012) investigou um grupo de 69 crianças com idades entre 1 e 5 anos, onde a prevalência de cárie era de $87 \%$. Esse alto índice deve-se à elevada ingestão diária de açúcar. Nesse estudo, os alimentos mais consumidos foram biscoito, macarrão, doces, achocolatados e salgadinhos.

Em contrapartida, um estudo feito por Souza (SOUZA FILHO et al., 2006), comprovou que crianças com boas condições socioeconômicas também possuem alta ingestão de alimentos cariogênicos. Todavia, a incidência da cárie é consideravelmente menor, devido as melhores condições de acesso a serviços odontológicos e hábitos de cuidado oral.

Segundo a Organização Mundial da Saúde (OMS, 2010), que utiliza o índice CPO com o objetivo de contabilização de dentes cariados, perdidos e restaurados, a incidência de cárie diminui em todas as regiões do Brasil, exceto a região norte. Fato que pode ser justificado, de acordo com Ardenghi (ARDENGHI et al., 2013), pelas diferenças socioeconômicas e raciais da população brasileira. Monteiro et al. (2000), afirmam que a baixa renda está intimamente ligada a falta de higiene oral, escassez de recursos, e menor acesso aos serviços odontológicos, bem como ao alto consumo de alimentos 
açucarados. Por esse motivo a OMS (2010) recomendou que o consumo de açúcar não exceda $10 \%$ das calorias consumidas durante o dia.

Nesse contexto, educadores e merendeiras capacitados podem tornar-se agentes transformadores, fazendo com que a escola se torne um local de promoção à saúde. Isso porque, esses profissionais são responsáveis pela transmissão de informações e conhecimentos aos escolares (LUZ, 2013). Assim, o ambiente escolar solidifica-se como um dos principais ambientes promotores de bons hábitos alimentares e de higiene bucal em crianças em fase escolar (ARAGÃO, 2010). Consequentemente, as crianças possuirão informações necessárias para a própria manutenção da saúde bucal.

\section{CONSIDERAÇÕES}

De acordo com os resultados obtidos em várias pesquisas, conclui-se que a alimentação atua efetivamente no aparecimento da doença cárie. Uma dieta saudável implica na saúde bucal e sistêmica da criança. Mesmo a doença sendo multifatorial, ela está intimamente ligada ao tipo de alimentação.

Assim sendo, a primeira infância é o melhor momento para o estabelecimento de hábitos adequados, uma vez que essa fase configura um momento importante do aprendizado. A escola é um ambiente propicio para a implementação de práticas corretas de alimentação e higiene bucal, visto que sua principal finalidade é a educação, além de possuir laços de afinidade entre alunos, professores e funcionários.

Dessa forma, os educadores e merendeiras podem influenciar os escolares de maneira positiva, visto que, estão em contato com os escolares em boa parte do dia. Para tanto, nutricionistas, cirurgiões-dentistas, educadores e merendeiras devem trabalhar em conjunto e de forma multidisciplinar para alcançar a qualidade de educação em saúde.

\section{REFERÊNCIAS}

ARAGÃO, A. K. R. Conhecimento de Professores das Creches Municipais de João Pessoa Sobre Saúde Bucal Infantil. Pesq Bras em Odontopediatria e Clínica Integrada, v.10, n.3, p.393-398. 2010. Disponível em: <http://www.redalyc.org/pdf/637/63717313010.pdf>. Acesso em: 23 jul. 2019.

ARDENGHI, Thiago Machado; PIOVESAN, Chaiana; ANTUNES, José Leopoldo Ferreira. Desigualdades na prevalência de cárie dentária não tratada em crianças pré-escolares no Brasil. Santa Maria - RS: Rev Saúde Pública, v.47, n.3, p. 129-137, 2013. Disponível em: < http://www.scielo.br/pdf/rsp/v47s3/0034-8910-rsp-47-supl300129.pdf>. Acesso em 23 jul. 2019

CARVALHO TP.; MASKE T.T.; SIGNORI C.; BRUNER K.V.; OLIVEIR E.F.D.; CENCI M.S. Desenvolvimento de lesões de cárie em dentina em um modelo de biofilme simplificado in vitro: um estudo piloto. Rev Odontol Unesp, v.47, n.1, p.40-44, 2018. Disponível em: < http://www.scielo.br/pdf/rounesp/v47n1/1807-2577-rounesp-1807-257706017.pdf>. Acesso em: 25 jul. 2019.

FEIJÓ, I.S.; IWASAKI, K.M.K. Cárie e Dieta Alimentar. Maringá: Uningá Review, v.19, n.3, p.44-50, 2014. Disponível em: < file://C:/Users/allan/Downloads/1551-13-4456-1-1020180115.pdf>. Acesso em: 03 ago. 2019. 
FERREIRA, G.C.; MIZAEL, V.P.; ARAUJO, T.G. F. Utilização no diário alimentar do consumo de sacarose em odontopediatria: revisão literária: Use of the food diary for diagnosing sucrose intake in pediatric dentistry: literature review. Pouso Alegre, Minas Gerais: Faculdade de Pouso Alegre, 2018. Disponível em: < http://docs.bvsalud.org/biblioref/2018/08/910191/8506.pdf>. Acesso em: 05 ago. 2019.

GARBIN, C. A. S.; ROVIDA, T. A. S.; PERUCHINI, L. F. D.; MARTINS R. J.. Conhecimento sobre saúde bucal e práticas desenvolvidas por professores do ensino fundamental. RFO. Passo Fundo, v.18, n.1, p.321-327, 2013.Disponível em: < http://revodonto.bvsalud.org/scielo.php?script=sci_arttext\&pid=S1413$40122013000300011 \&$ Ing=pt\&nrm=iso >. Acesso em: 03 ago. 2019.

\section{LIMA JUNIOR, J.L.A.; GONÇALVES, L.V.; CORREIA, A.A. Alimentos $x$ cárie: a} ingestão do açúcar em excesso como fator estimulante do desenvolvimento da doença. Recife: Ciências Biológicas e da Saúde, v.2, n.2,p.11-20, 2015. Disponível em: < file:///C:/Users/allan/Downloads/3060-8857-1-SM\%20(1).pdf>. Acesso em: 03 ago. 2019.

LUZ, Sandra Ferrari. Plano de ação para reduzir a prevalência de cárie dentária em crianças de quatro e cinco anos, assistidas em creches de uma unidade de ESF de Governador Valadares/MG. Governador Valadares, Minas Gerais: Universidade Federal de Minas Gerais, 2013. Disponível em:

<https://www.nescon.medicina.ufmg.br/biblioteca/imagem/4180.pdf>. Acesso em: 25 ago. 2019.

Ministério Da Saúde. Disponível em: http://portal.saude.gov.br/saude/. Acesso em 15/06/2014.

MONTEIRO CA; MONDINI L.; COSTA RBL. Mudanças na composição e adequação nutricional da dieta familiar nas áreas metropolitanas do Brasil (1988-1996). Rev Saude Publica, v.34, n.3, p. 251-258, 2000. Disponível em: < http://www.scielo.br/scielo.php?script=sci_arttext\&pid=S0034-89102000000300007>. Acesso em: 03 ago. 2019.

SCALIONI, A.R. Hábitos de dieta e cárie precoce da infância em crianças atendidas em faculdade de odontologia brasileira pesquisa brasileira em odontopediatria e clínica integrada.

Disponível em: <http://oai.redalyc.org/articulo.oa?id=63724514016>. Acesso em: 17 jul. 2015.

SOUZA FILHO, M.D.; CARVALHO, G.D.F.; MARTINS, M.C.C. Consumo de alimentos ricos em açúcar e cárie dentária em pré-escolares. Arq. Odontol., v.46, n.3, Belo Horizonte, set. 2010.

Disponível em: <http://revodonto.bvsalud.org/scielo.php?script=sci_arttext\&pid=S151609392010000300005\&lng=es\&nrm=iso >. Acesso em: 17 jul. 2015.

VENÂNCIO, D. R.; GIBILINI, C.; BATISTA, M. J.; GONÇALO, C. S.; SOUSA, M. L. R. Promoção da saúde bucal: desenvolvendo material lúdico para crianças na faixa etária pré- escolar. J Health Sci Inst. v.29, n.3, p.153-156. 2011. Disponível em: <https://w2.fop.unicamp.br/dos/saudecoletiva/downloads/atividades_extra_muro/atividade s_teatro_escolas/promovendo_material_ludico_para_criancas.pdf>. Acesso: 01 ago. 2019. 